\title{
Carbon tetrachloride induced hepatorenal toxicity in rats: possible protective effects of wild Pleurotus tuber-regium
}

\author{
Kenneth Obinna Okolo ${ }^{1}$, Iyeopu Minakiri Siminialayi ${ }^{2}$ and Orish Ebere Orisakwe ${ }^{3^{*}}$
}

\begin{abstract}
Background: The economic cost of and liver and kidney diseases in Sub Saharan Africa remain prohibitive, hence the quest for medicinal foods that can reverse hepato-renal damages. The aim of this study is to investigate the hepato-renal protective effect of wild edible P.tuber-regium on carbon tetrachloride $\left(\mathrm{CCl}_{4}\right)$ induced oxidative stress in male Sprague-Dawley rats.
\end{abstract}

Method: Thirty six rats were divided into six groups of six animals each. Group I (negative control) received $10 \mathrm{ml} /$ $\mathrm{kg}$ olive oil intraperitoneal weekly in addition to feed and water ad libitum. Group II (positive control) received $\mathrm{CCl}_{4}$ $10 \mathrm{ml} / \mathrm{Kg}$ (30\% in Olive oil) weekly. Group III, IV and V received $100 \mathrm{mg}, 200 \mathrm{mg}$ and $500 \mathrm{mg}$ wild edible P.tuberregium (33.3\% in feed) daily in addition to $10 \mathrm{ml} / \mathrm{Kg} \mathrm{CCl}$ weekly. Group VI received $500 \mathrm{mg}$ P.tuber-regium (33.3\% in feed) daily. After four weeks, the serum levels of alanine aminotransferase (ALT), aspartate aminotransferase (AST), alkaline phosphatase (ALP), creatinine, bilirubin, urea and fasting blood glucose were determined. Also, the histopathologic examinations of the kidney and liver were carried out.

Results: Administration of $\mathrm{CCl}_{4}$ to rats significantly $(p<0.05)$ decreased the levels of Bilirubin $(1.21 \pm 0.07)$, Creatinine $(0$. $91 \pm 0.04)$ and Urea $(45.76 \pm 3.10 \mathrm{mg} / \mathrm{dl})$ when compared to control $(0.66 \pm 0.07,0.76 \pm 0.05$ and $24.48 \pm 4.70$ respectively). Liver and kidney MDA from $14.00 \pm 2.60$ and $14.00 \pm 3.50$ in CCl4 only treated groups to $8.60 \pm 1.5$ and $1.70 \pm 0.15 \mu \mathrm{mol} /$ $\mathrm{mg}$ in the $500 \mathrm{mg}$ P.tuber-regium treated groups. Photomicrographs also showed that P.tuber-regium prevented the fibrosis of the bile duct, glomeruli and tubules seen in $\mathrm{CCl}_{4}$ group.

Conclusion: P.tuber-regium may be protective against the $\mathrm{CCl}_{4}$ induced oxidative damage of the hepato-renal system.

Keywords: Pleurotus tuber-regium, $\mathrm{CCl}_{4}$, Mushroom, Liver and renal biomarkers, Antioxidant histopathology

\section{Background}

Despite recent developments in medical sciences, treatment of diseases relating to liver and kidney is very expensive, relatively unavailable with high incidence of adverse effects and failure [1]. This spurs the need for a more efficient, cost effective and easily available regime to combat liver and kidney pathologies especially in the developing nations. Natural products with their secondary metabolites may be efficacious and possess antioxidant potentials that scavenge free radicals and reduce oxidative stress [2]. Edible mushrooms had been used in the treatment of different ailments

\footnotetext{
* Correspondence: orishebere@gmail.com

${ }^{3}$ Department of Experimental Pharmacology and Toxicology, Faculty of Pharmacy, University of Port-Harcourt, Port-Harcourt, Rivers State, Nigeria Full list of author information is available at the end of the article
}

in folk medicine and possesses secondary metabolites that could treat or slow down the pathogenesis of diseases like liver and kidney pathologies [3, 4].

Pleurotus tuber-regium a fungus that grows on drill dust of the wood Treculia Africana (bread fruit), Elaeis guineensis, or Daniella oliver tree. It belongs to the genus basidiomycete, and is found mainly in the tropics and subtropics. It forms a large spherical to ovoid sclerptia (underground tuber) [5]. Pleurotus tuber-regium is a popular edible mushroom found in decaying vegetation [6] that had been attributed with many medicinal properties like anticancer, anti-inflammatory, antihypertensive, antilipidemic and antidiabetic [6-8]. Edible mushrooms are known to contain several secondary metabolites like phenolic, tannins, alkaloids, and flavonoids etc. that 
account for their diverse pharmacological activities and in some instance their antioxidant properties. Antioxidants in mushrooms are known to combat free radical mediated injuries via its unique ability to donate electrons and therefore stabilize highly reactive free radicals [9].

The aim of this study is to evaluate the hepato-renal protective activity of P.tuber-regium in a free radical model using rat.

\section{Methods}

\section{Harvesting of the mushroom}

Fresh fruiting bodies of wild P.tuber-regium were collected from a forest at the back of University of Nigeria Nsukka by a taxonomist working with the university. These fresh fruiting bodies were cleaned and air dried away from direct sunlight. The mushroom were ground and stored in a clean dry plastic container until use [10]. Little is known about bacterial contamination of the Nigerian harvested P.tuber-regium. P.tuber-regium were not tested for micriobiological contaminations

\section{Animals husbandry}

Thirty six male Sprague-Dawley rats with body weights 180-200 g acclimatized for two weeks were maintained under controlled conditions of temperature $\left(23 \pm 2{ }^{\circ} \mathrm{C}\right)$ and humidity $(50 \pm 5 \%)$ and a 12 -h light-dark cycle, were used for the experiment. The animals were housed in sanitized polypropylene cages containing sterile paddy husk as bedding. The bedding of the cages was changed daily and the cages were cleaned as well. They had free access to standard rat

pellet diet and water ad libitum. All the experimental procedures were performed according to the committee for the purpose of control and supervision of experiments on animals, norms and approved by the University of Port Harcourt Animal Ethical Committee with an approval number UNIPORT/PHARM/0133.

\section{Carbon tetrachloride $\left(\mathrm{CCl}_{4}\right)$}

Thirty percent carbon tetrachloride (Sigma Aldrich) in Olive oil [11] was used to induce renal and hepatic damage at a dose of $10 \mathrm{ml} / \mathrm{kg}$ (i.p) [12].

\section{Acute toxicity studies}

Different concentrations of P.tuber-regium (50-5000 mg/kg body weight b.w.) were administered orally to male rats. These animals were observed daily for toxicological manifestations like behavioral changes, neural and autonomic toxicities, feeding pattern changes etc. There was no mortality recorded during this period even up to the dose of $5000 \mathrm{mg} / \mathrm{kg}$ [13].

\section{Experimental design}

The animals were divided into six groups with each group consisting of six animals each. The administration of $\mathrm{CCl}_{4} 10 \mathrm{ml} / \mathrm{kg}$ body weight of $30 \% \mathrm{CCl}_{4}$ in olive oil was given on days $0,7,14$, and 21 concomitantly with the daily feeding of the mushroom.

The animals were treated for 4 weeks as follows

Group I - normal control received olive oil $10 \mathrm{ml} /$ kg i.p. weekly in addition to standard food and water. Group II - Positive control received $\mathrm{CCl}_{4}(30 \% \mathrm{CCl} 4$ in olive oil) at a dose of $10 \mathrm{ml} / \mathrm{kg}$ weekly in addition to standard feed and water.

Group III - rats were treated orally with $100 \mathrm{mg} / \mathrm{kg}$ b.w. of P.tuber-regium in feed $(33.3 \% \mathrm{w} / \mathrm{w})$ along with $10 \mathrm{ml} / \mathrm{kg} \mathrm{CCl}_{4}$ (30\% in olive oil) weekly.

Group IV - rats were treated orally with $200 \mathrm{mg} / \mathrm{Kg}$ b.w. of P.tuber-regium in feed $(33.3 \% \mathrm{w} / \mathrm{w})$ along with $10 \mathrm{ml} / \mathrm{kg} \mathrm{CCl}_{4}$ (30\% in olive oil) weekly.

Group V - rats were treated orally with $500 \mathrm{mg} / \mathrm{kg}$ b.w. of P.tuber-regium in feed $(33.3 \% \mathrm{w} / \mathrm{w})$ along with

$10 \mathrm{ml} / \mathrm{kg} \mathrm{CCl}_{4}$ (30\% in olive oil) weekly. In all $\mathrm{CCl}_{4}$ was given intraperitoneally.

Group VI - rats were treated orally with $500 \mathrm{mg} / \mathrm{kg}$ b.w. of P.tuber-regium in feed $(33.3 \% \mathrm{w} / \mathrm{w})$ only with standard feed and water.

\section{Necropsy}

Animals were sacrificed $24 \mathrm{~h}$ after the last treatment. Blood was collected by retero orbital sinus puncture and serum was separated by centrifugation at 3000 r.p.m for $10 \mathrm{mins}$ at $4{ }^{\circ} \mathrm{C}$ for assay of biochemical parameters. Rats were sacrificed under ether anesthesia; liver and kidney were excised, rinsed clean in saline, weighed and preserved in $10 \%$ formalin for histopathological study.

\section{Determination of biochemical parameters}

Commercial reagent kits for the determination of bilirubin, cholesterol, creatinine and urea concentrations and alanine aminotransferase (ALT), aspartate aminotransferase (AST), alkaline phosphatase (ALP), were assayed using Quimica Clinica Aplicada (QCA) Spain. Fasting blood glucose was determined using commercial glucometer made by accu-chek.

\section{Antioxidant assay}

The liver and kidney were minced separately into small pieces and homogenzed with ice cold $0.05 \mathrm{M}$ potassium phosphate buffer ( $\mathrm{pH} 7.4$ ) to make $10 \%$ homogenates. The homogenates were centrifuged at $6000 \mathrm{rpm}$ for 15 mins at $4{ }^{\circ} \mathrm{C}$. The supernatant was collected for the estimation superoxide dismutate (SOD) and malondialdehyde (MDA) assays. Superoxide dismutate (SOD) was assayed by the method described by Misra and Fridovich 


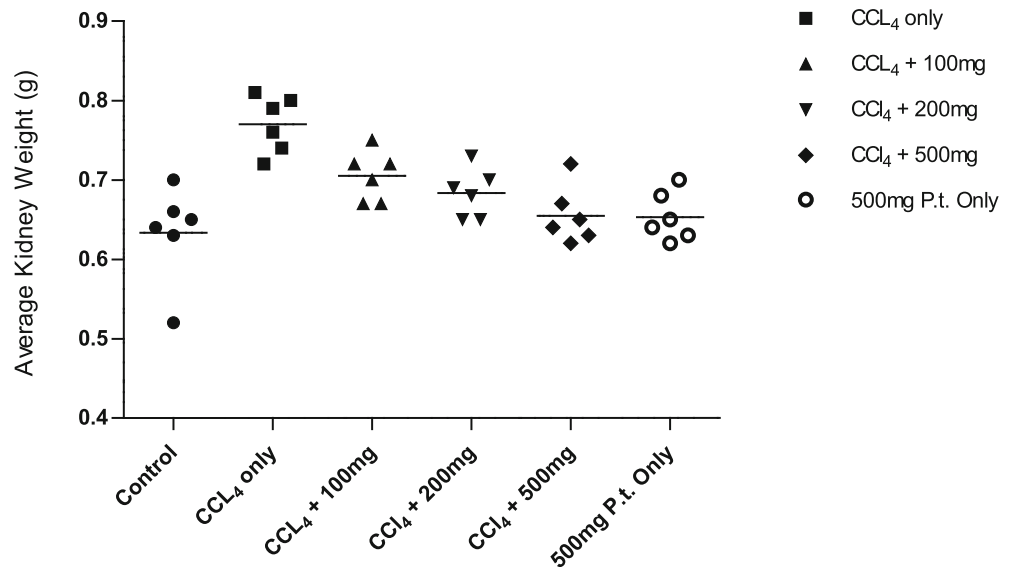

Fig. 1 Effect of Pleurotus tuber-regium treatment on the average kidney weight of $\mathrm{CCl}_{4}$ administered rats

[14]. Lipid peroxidation was quantified as malondialdehyde (MDA) according to the method described by Ohkawa et al. [15]. and the MDA level was calculated according to the method of Todorova et al. [16] and expressed as $\mu \mathrm{mol} \mathrm{MDA} / \mathrm{mg}$ protein.

\section{Histopathological studies}

Portions of the liver and kidney from all the experimental groups were fixed in 10\% formaldehyde, dehydrated in graded alcohol, cleared in xylene and then embedded in paraffin. Microtome sections ( $5 \mu \mathrm{m}$ thick) were prepared from each liver and kidney sample and stained with heamtoxylin-eosin (H\&E) dye. The sections were examined for the pathological findings.

\section{Statistical analysis}

Data obtained were analyzed using graph pad prism 5 . The values represent means and their standard deviations. Differences between the means were determined using one way analysis of variance (one way ANOVA) followed by Bonferroni's test. P values of 0.05 or less were considered statistically significant.

\section{Results}

Effect of P.tuber-regium on the liver weight of $\mathrm{CCl}_{4}$ treated animals

Figures 1 and 2, shows the effect of the P.tuber-regium on the weights of the liver and kidney after administration of $\mathrm{CCl}_{4}$. Administration of $\mathrm{CCl}_{4}$ to the rats resulted in a significant $(p<0.05)$ increase in the absolute $(0.77 \pm 0.04)$

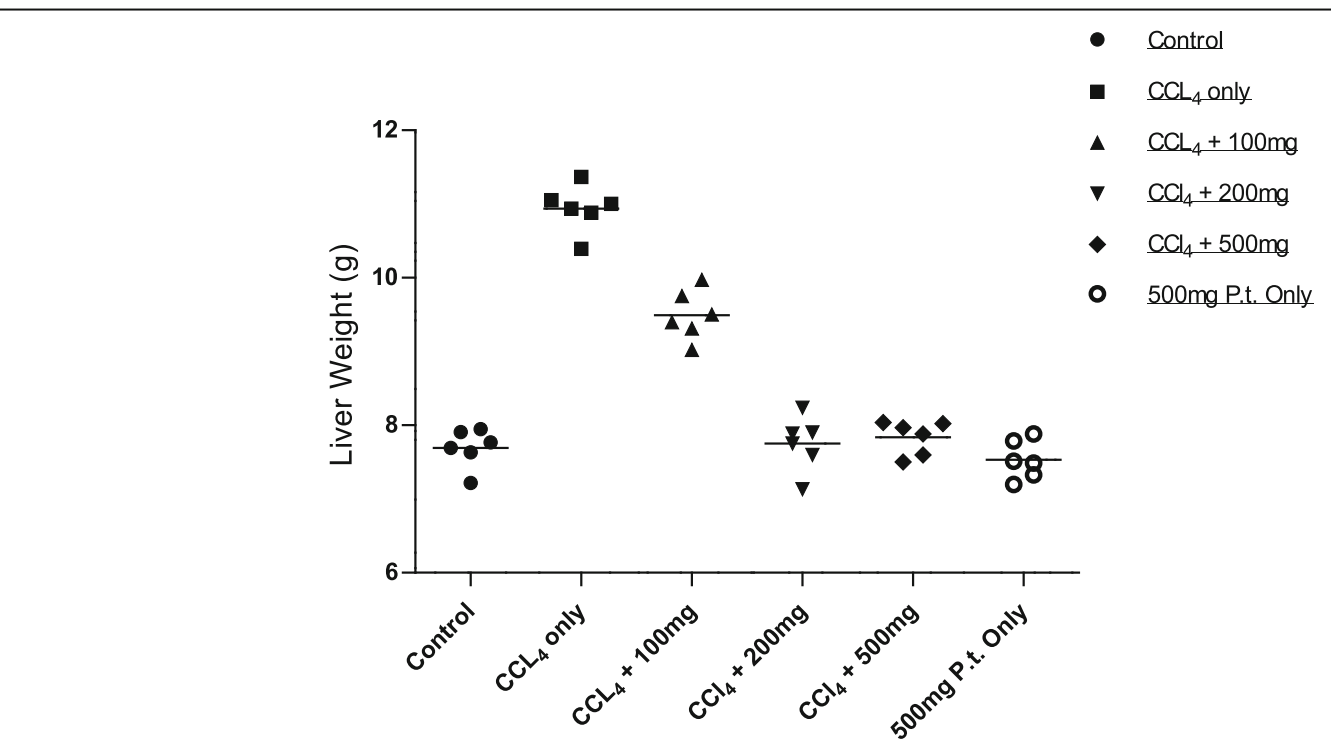

Fig. 2 Effect of Pleurotus tuber-regium treatment on the liver weight of $\mathrm{CCl}_{4}$ administered rats 
Table 1 Effect of P.tuber-regium on ALT, AST and ALP

\begin{tabular}{|c|c|c|c|}
\hline Treatment & ALT (iu/L) & AST (iu/L) & ALP (iu/L) \\
\hline Control & $26.85 \pm 2.63$ & $75.68 \pm 5.20$ & $293.10 \pm 15.15$ \\
\hline $\mathrm{CCl}_{4}$ Only & $42.82 \pm 2.70^{* * *}$ & $92.97 \pm 6.34^{* *}$ & $421.10 \pm 12.89^{* * *}$ \\
\hline $\mathrm{CCl}_{4}+100$ mg P.t. & $34.67 \pm 1.34$ & $83.98 \pm 5.18$ & $352.90 \pm 15.44$ \\
\hline $\mathrm{CCl}_{4}+200 \mathrm{mg}$ P.t. & $29.82 \pm 8.34$ \#\# & $78.47 \pm 4.533^{\# \#}$ & $331.60 \pm 12.76^{\#}$ \\
\hline $\mathrm{CCl}_{4}+500 \mathrm{mg}$ P.t. & $30.74 \pm 5.53^{\# \#}$ & $78.09 \pm 8.23^{\# \#}$ & $336.70 \pm 16.22$ \# \\
\hline 500 mg P.t. Only & $26.64 \pm 2.45$ \#\#\# & $75.74 \pm 4.68$ \#\#\# & $263.00 \pm 13.92^{\# \# \#}$ \\
\hline
\end{tabular}

and relative weight $(0.40 \pm 0.04 \mathrm{~g})$ of the kidneys in all the treatment groups when compared to control (absolute $0.63 \pm 0.03$ and relative $0.34 \pm 0.01 \mathrm{~g})$. Carbon tetrachloride significantly $(p<0.05)$ increased in both the absolute $(10.94 \pm 0.41)$ and relative weights $(5.70 \pm 0.21)$ of the liver in all the treated groups when compared to the control. There was a significant dose - dependent reduction in the weights of the liver and kidney in the rats that received CCl4 and P.tuber-regium.

The effect of P.tuber-regium on the Liver function tests: ALT, AST and ALP are shown on Table 1. Administration of $\mathrm{CCl}_{4}$ significantly $(p<0.05)$ increased the liver enzymes ALT $(42.82 \pm 2.70)$, AST $(92.97 \pm 6.34)$ and ALP (421.10 \pm $12.89 \mathrm{iu} / \mathrm{L})$ in all the treated rats when compared to control rats $26.85 \pm 2.63 .75 .68 \pm 5.20$ and $293.10 \pm 15.15 \mathrm{iu} / \mathrm{L}$ respectively. In the $\mathrm{CCl}_{4}$ plus P.tuber-regium treated groups 200 and $500 \mathrm{mg}$ P.tuber-regium tended to significantly reverse the effects of $\mathrm{CCl}_{4}$ on the ALT, AST and ALP in dose dependent fashion. Administration of P.tuber-regium at $500 \mathrm{mg}$ only without $\mathrm{CCl}_{4}$ showed no significant $(p<0.05)$ difference from the control.

\section{Effect of P.tuber-regium on the Kidney function tests}

Administration of $\mathrm{CCl}_{4}$ to rats significantly $(p<0.05)$ decreased the serum levels of Bilirubin (1.21 \pm 0.07$)$, Creatinine $(0.91 \pm 0.04)$ and Urea $(45.76 \pm 3.10 \mathrm{mg} / \mathrm{dl})$ when compared to control $(0.66 \pm 0.07,0.76 \pm 0.05$ and 24.48 \pm 4.70 respectively) (Table 2 ). Also, fasting blood glucose was increased significantly $(p<0.05)$ when compared to control from $75.67 \pm 2.94$ to $90.60 \pm 4.62 \mathrm{mg} / \mathrm{dl}$. Treatment with P.tuber-regium restored the levels of these markers in a dose dependent manner when compared to the control group. However, treatment with P.tuberregium alone did not cause any significant $(p<0.05)$ change in the markers studied as compared to the control group.

The effect of P.tuber-regium on the superoxide dismutase (SOD) and malondialdehyde

(MDA) in liver and kidney is shown on Table 3. There was significant increase in the MDA of kidney $1.40 \pm$ 0.32 (control) and $14.00 \pm 3.50\left(\mathrm{CCl}_{4}\right)$ and liver $1.90 \pm$ 0.42 (control) and $14.00 \pm 2.60\left(\mathrm{CCl}_{4}\right)$ treated groups. The superoxide dismutase (SOD) in the liver and kidney were also significantly decreased from $7.58 \pm 0.59$ and $8.49 \pm 0.38$ in control to $1.65 \pm 0.48$ and $3.18 \pm 0.31 \mu \mathrm{g} /$ mg protein after $\mathrm{CCl}_{4}$ administration. P.tuber-regium administration decreased the level of MDA and increased the level of SOD in the $\mathrm{CCl}_{4}$ treated groups significantly in dose dependent manner.

\section{Histological studies of the liver}

The histological architecture of the liver in control rats showed normal and well preserved structures with the hepatocytes well arranged around a central vein with alternations of blood sinusoids. The liver cells show a membrane, a nucleus and nucleoli (Fig. 3a). Examination of the hepatocytes of $\mathrm{CCl}_{4}$ treated rats show proliferation of bile duct epithelium with dilated and congested sinusoids (Fig. 3b). Treatment with P.tuber-regium reversed these changes (Fig. $3 \mathrm{c}, \mathrm{d}$ and e) with the reversal being more pronounced in the higher dose of $500 \mathrm{mg}$ P.tuber-regium. Examination of P.tuber-regium only group shows a well preserved and normal hepatic cells comparable the control (Fig. 3f).

\section{Histological studies of the kidney}

The histological studies of the kidney showed normal well preserved architecture of the kidney with normal glomeruli and tubules (Fig. 4a). Administration of $\mathrm{CCl}_{4}$ markedly

Table 2 Effect of P.tuber-regium on bilirubin, creatinine urea and fasting blood glucose

\begin{tabular}{|c|c|c|c|c|}
\hline Treatment & $\begin{array}{l}\text { Bilirubin } \\
(\mathrm{mg} / \mathrm{dL})\end{array}$ & $\begin{array}{l}\text { Creatinine } \\
(\mathrm{mg} / \mathrm{dL})\end{array}$ & $\begin{array}{l}\text { Urea } \\
(\mathrm{mg} / \mathrm{dL})\end{array}$ & $\begin{array}{l}\text { Fasting Blood Glucose } \\
(\mathrm{mg} / \mathrm{dL})\end{array}$ \\
\hline Control & $0.66 \pm 0.07$ & $0.76 \pm 0.05$ & $24.48 \pm 4.70$ & $75.67 \pm 2.94$ \\
\hline $\mathrm{CCl}_{4}$ Only & $1.21 \pm 0.07^{* *}$ & $0.91 \pm 0.04^{* *}$ & $45.76 \pm 3.10^{* * *}$ & $90.60 \pm 4.62^{* * *}$ \\
\hline $\mathrm{CCl}_{4}+100$ mg P.t. & $0.99 \pm 0.04$ & $0.82 \pm 0.07$ & $35.47 \pm 11.68$ & $79.25 \pm 8.30^{\#}$ \\
\hline $\mathrm{CCl}_{4}+200$ mg P.t. & $0.78 \pm 0.02^{\#}$ & $0.79 \pm 0.03^{\#}$ & $27.31 \pm 7.13^{\# \#}$ & $76.50 \pm 3.79^{\# \#}$ \\
\hline $\mathrm{CCl}_{4}+500$ mg P.t. & $0.73 \pm 0.09^{\#}$ & $0.76 \pm 0.05^{\# \#}$ & $27.88 \pm 6.44$ & $76.25 \pm 4.35$ \#\# \\
\hline 500 mg P.t. Only & $0.66 \pm 0.09$ \#\# & $0.75 \pm 0.06^{\# \#}$ & $24.25 \pm 4.73$ & $75.00 \pm 3.92$ \#\# \\
\hline
\end{tabular}

Each value represents mean $\pm \mathrm{SD}, n=6$. Values marked with an asterisk $\left(^{*}\right)$ differ significantly from control value $\left({ }^{* *} p<0.01, * * * p<0.001\right)$ while those marked with \# differ significantly from $\mathrm{CCl}_{4}$ only group $\left({ }^{\#} p<0.05,{ }^{\# \#} p<0.01,{ }^{\# \# \#} p<0.001\right)$ 
Table 3 Effect of P.tuber-regium on the superoxide dismutate (SOD) and malondialdehyde (MDA) in liver and kidney

\begin{tabular}{lllllll}
\hline & Groups & Control & $\mathrm{CCL}_{4}$ Only & $\mathrm{CCL}_{4}+100 \mathrm{mg}$ P.t. & $\mathrm{CCL}_{4}+200 \mathrm{mg}$ P.t. & $\mathrm{CCL}_{4}+500 \mathrm{mg} \mathrm{P.t.}$ \\
\hline MDA $(\mu \mathrm{mol} / \mathrm{mg})$ & Kidney & $1.40 \pm 0.32$ & $14.00 \pm 3.50^{* * *}$ & $3.50 \pm 0.61^{\# \# \#}$ & $1.60 \pm 0.36^{* * *}$ & $1.70 \pm 0.15^{\# \# \#}$ \\
& Liver & $1.90 \pm 0.42$ & $14.00 \pm 2.60^{* * *}$ & $10.00 \pm 1.80^{* * *}$ & $8.90 \pm 1.00^{* * \#}$ & $8.60 \pm 1.5^{* * \# \#}$ \\
SOD $(\mu \mathrm{g} / \mathrm{mg}$ protein) & Kidney & $8.49 \pm 0.38$ & $2.78 \pm 0.30^{* * *}$ & $3.18 \pm 0.31^{* * *}$ & $5.31 \pm 0.37^{* * * \# \# \#}$ & $6.48 \pm 0.50^{* * * \# \# \#}$ \\
& Liver & $7.58 \pm 0.59$ & $1.48 \pm 0.33^{* * *}$ & $1.65 \pm 0.48^{* * *}$ & $3.60 \pm 0.36^{* * * \# \#}$ & $3.88 \pm 0.47^{* * * \# \#}$ \\
\hline
\end{tabular}

Each value represents mean $\pm \mathrm{SD}, n=6$. Values marked with an asterisk $\left(^{*}\right)$ differ significantly from control value $\left({ }^{* *} p<0.01,{ }^{* * *} p<0.001\right)$ while those marked with \# differ significantly from $\mathrm{CCl}_{4}$ only group $\left({ }^{\#} p<0.05,{ }^{\# \#} p<0.01\right.$, \#\#\# $\left.p<0.001\right)$

disrupted the normal architecture of the kidney cell by degenerating the tubules and collapsing the glomerulus (Fig. 4b). Treatment with P.tuber-regium improved these pathological changes in a dose dependent manner (Fig. 4c, $\mathrm{d}$ and e). Slides of the $500 \mathrm{mg}$ P.tuber-regium only group showed well preserved architecture comparable to the control (Fig. 4f).

\section{Discussion}

Carbon tetrachloride is a reference toxicant in mammalian systems with established toxicities in the kidney, liver, testis, heart, lungs etc. $[17,18]$. Once injected into a mammalian system, it undergoes extensive biotransformation in the livers P-450 system to generate trichloromethyl radical $\left(\mathrm{CCl}_{3}{ }^{\circ}\right)$ and chloride radical $\mathrm{Cl}^{\circ}$ which being electron deficient, have very high affinity for electrons in biological tissues. This extortion of electrons from biological systems leads to peroxidation of proteins, distortion of enzymes and DNA [19]. In this study, we tested the hypothesis that wild edible mushrooms like P.tuber-regium could protect against $\mathrm{CCl}_{4}$ induced hepato-renal toxicity.
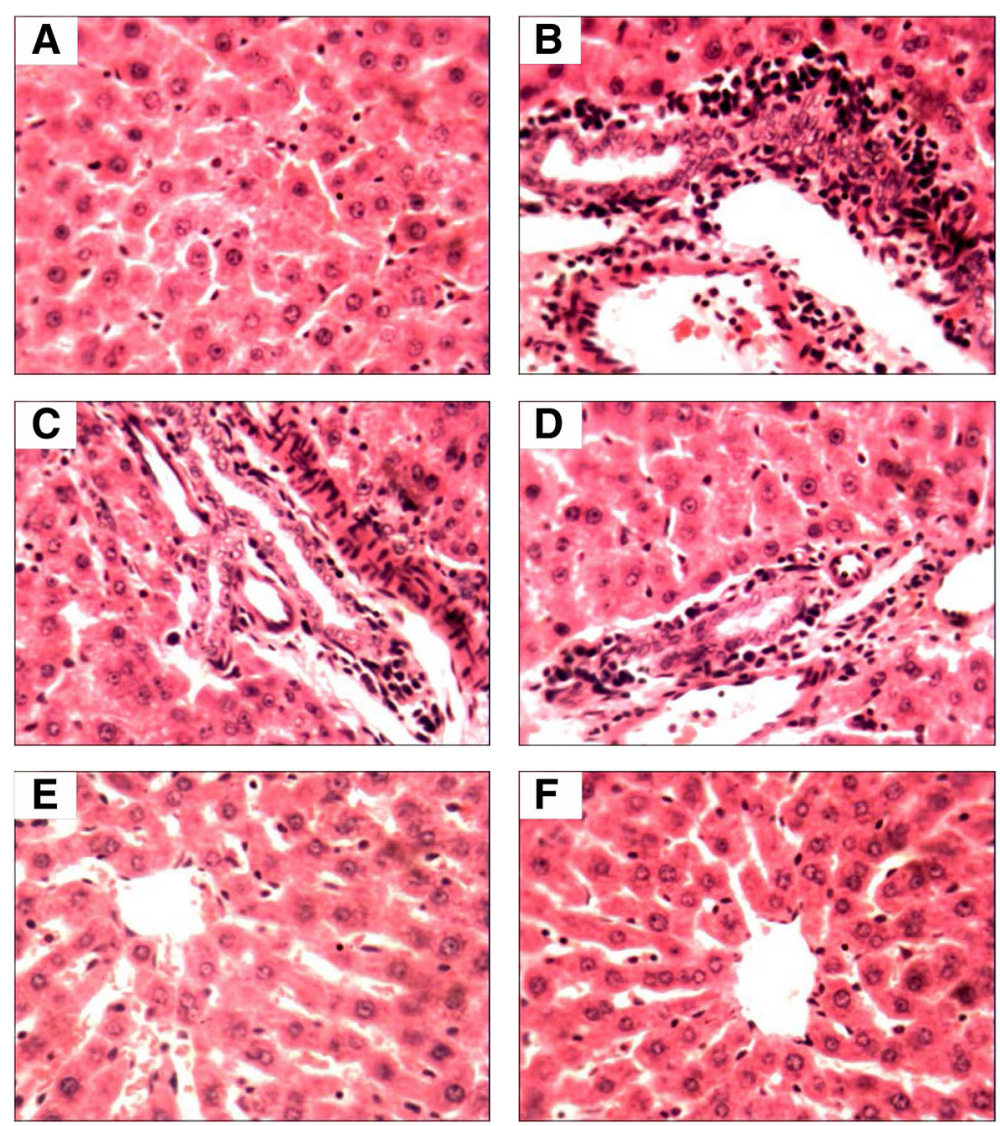

Fig. 3 Histopathology showing the alterations induced with $\mathrm{CCl}_{4}$ and preventive effects of P.tuber-regium in hepatic tissues. a Hepatic section showing the normal architecture of the liver (b) $\mathrm{CCl}_{4}$ induced injuries with severe proliferation of bile ducts and congested sinusoids (c, $\mathbf{d}$ and $\mathbf{e}$ ) $\mathrm{CCl}_{4}$ induced injuries and protective effect of P.tuber-regium in a dose dependent manner (f) A well preserved architecture of the hepatocytes comparable to the control 

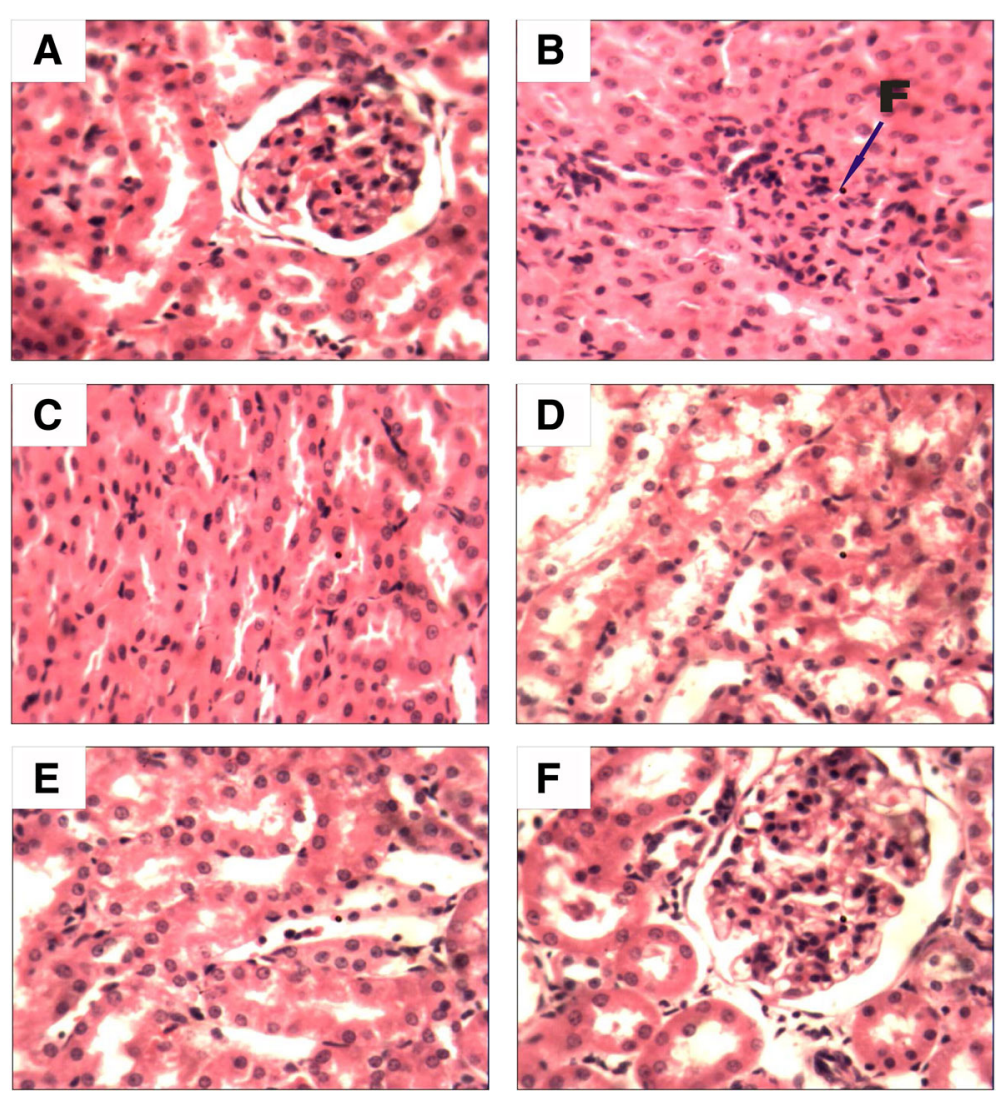

Fig. 4 Photomicrograph showing the alterations induced with $\mathrm{CCl}_{4}$ and preventive effects of P.tuber-regium in nephrotic tissues. a Normal structure of nephrotic tissue showing well preserved glomerulus and tubules. $\mathbf{b}$ Nephrotic alterations induced with $\mathrm{CCl}_{4}$ with pronounced tubules and glomeruli due to fibrosis (f). $\mathbf{c}, \mathbf{d}$ and $\mathbf{e}$ alterations in the nephrotic tissue following $\mathrm{CCl}_{4}$ intoxication and the protective effect of Pleurotus tuber-regium in a dose dependent manner. $\mathbf{f}$ A well preserved nephron comparable to the control

Administration of $\mathrm{CCl}_{4}$ resulted in significant $(p<$ 0.05 ) increases in both the absolute and relative weights of the liver and kidney when compared with the control. This increase in liver and kidney weights may be attributed to lesions and injuries associated with xenobiotics [2] like $\mathrm{CCl}_{4}$ which peroxidizes cell proteins thereby activating the inflammatory pathway. This is evident from the photomicrographs of both the kidneys and liver that showed proliferation of the bile ducts, tubules and the glomeruli. The enlargement of the liver and kidney were significantly reduced in the treatment groups that received P.tuber-regium suggesting that the mushroom contains some protective phytomedicinals. This result is in agreement with other works on mushrooms in a free radical mediated injury where mushroom reduced oxidative stress mediated injury by gentamicin [2].

The treatment of rats with $\mathrm{CCl}_{4}$ caused a significant increase in the serum levels of liver and kidney biomarkers like Bilirubin, Creatinin, Urea, Fasting blood glucose FBG, ALT, AST and ALP. The implication of these observations is possible hepato-renal dysfunction as a result of the free radicals; trichloromethyl radical
$\left(\mathrm{CCl}_{3}{ }^{\circ}\right)$, trichloromethylperoxy radical $\left(\mathrm{OOCCl}_{3}{ }^{\circ}\right)$, chloride radical $\left(\mathrm{Cl}^{\circ}\right)$ etc. generated by the $\mathrm{CCl}_{4}$ following biotransformation by CYP 2E1 of the liver [20]. These radicals being electron deficient react with electron rich proteins to cause peroxidation of macromolecules like the membranes with subsequent leakage of the enzymes into the serum [21]. Some of these leaked enzymes found in the serum like ALT, AST and ALP are biomarkers of liver that is elevated during hepatotoxicity. This result is agreement with other works that had recorded elevated serum levels of liver markers following $\mathrm{CCl}_{4}$ intoxication [22]. These elevated biomarkers of liver toxicity were markedly reduced by the administration of P.tuber-regium in a dose dependent manner. P.tuber-regium is known to be rich in antioxidant molecules like phenolics, tannins, flavonoids [22] which are efficient electron donor thereby helping to terminate free radical reaction. This process spares the body's antioxidant systems and macromolecules which are the primary targets of peroxidation. The protective effect in the liver is also seen in the photomicrographs with well-preserved structures comparable to untreated control group. 
The protective activity of P.tuber-regium seen in the liver was also seen in the kidney. The major renal biomarkers suggested significant renoprotection in a dose dependent manner after administration P.tuber-regium, which may be due to anti- oxidative stress mechanism [23]. The significant increase in SOD and decrease in MDA following P.tuber-regium administration in CCl4 treated animals lend credence to the antioxidant potential of this mushroom and its folkloric use. The oxidation of membrane lipid bilayer affected lipid structures of the nephron which resulted in a subcellular structural damage as revealed by the micrographs of the kidney (tubular and glomerular fibrosis). These finding are similar to the protection observed with Digera muricata where the structural changes observed in $\mathrm{CCl}_{4}$ group were attenuated [24]. This hepato-renal protective effectof P.tuber-regium may be due to the presence of antioxidant phytochemicals that may not only attenuate the toxicity of $\mathrm{CCl}_{4}$ but may have restorative properties.

The histopathological findings have provided direct evidence of the possibility of the P.tuber-regium to attenuate the disruption of structure of both the liver and kidney cells. These observations complemented the results of the cytoplasmic enzymes namely (alanine aminotransferase (ALT), aspartate aminotransferase (AST), alkaline phosphatase (ALP), and bilirubin, creatinine and urea concentrations. A direct radical-scavenging activity of the P.tuber-regium might be involved in the hepatoand nephron-protective activity against $\mathrm{CCl}_{4}$ exposure.

\section{Conclusion}

Taken together it may be concluded that the P.tuberregium is able to combat the effect of $\mathrm{CCl}_{4}$ exposure in albino rats, which might be attributed to its antioxidant defense mechanism.

\section{Acknowledgements}

\section{Authors' contributions}

KOO: Designed study, carried out the bench work and analysed data. IMS Design. OEO: Designed the study, analysed data and write up. All authors read and approved the final manuscript.

\section{Competing interests}

The authors declare that they have no competing interests.

\section{Source of support}

Nill.

\footnotetext{
Author details

'Department of Pharmacology and Toxicology, Faculty of Pharmacy, Madonna University, Port Harcourt, Elele Rivers State, Nigeria. ${ }^{2}$ Department of Pharmacology, Faculty of Basic Medical Sciences, College of Health Sciences, University of Port Harcourt, Port Harcourt, Rivers State, Nigeria. ${ }^{3}$ Department of Experimental Pharmacology and Toxicology, Faculty of Pharmacy, University of Port-Harcourt, Port-Harcourt, Rivers State, Nigeria.
}

Received: 9 September 2016 Accepted: 15 December 2016 Published online: 05 January 2017

\section{References}

1. Stickel F, Schuppan D. Herbal medicine in the treatment of liver diseases. Dig Liver Dis. 2007;39(4):293-304.

2. Wong WL, Abdulla MA, Chua KH, Kuppusamy UR, Tan YS, Sabaratnam V. Hepatoprotective effects of Panus giganteus (Berk.) Corner against thioacetamide-(TAA-) induced liver injury in rats. Evid Based Complementary Altern Med. 2012;2012:170303.

3. Ao ZH, Xu ZH, Lu ZM, Xu HY, Zhang XM, Dou WF. Niuchangchih (Antrodia camphorata) and its potential in treating liver diseases. J Ethnopharmacol. 2009;121(2):194-212

4. Shi Y, Sun J, He H, Guo H, Zhang S. Hepatoprotective effects of Ganoderma lucidum peptides against D-galactosamine-induced liver injury in mice. J Ethnopharmacol. 2008:117(3):415-9.

5. Okhuoya JA, Okogbo FO. Induction of edible sclerotia of Pleurotus tuberГCCÉregium (FR) Sing, in the laboratory. Ann Appl Biol. 1990;117:295-8.

6. Ifeoma I, Ikechukwu A, Princess C, Henry I. Phytochemical composition of Pleurotus tuber regium and effect of its dietary incorporation on body/ organ weights and serum triacylglycerols in albino mice. J Med Plants Res. 2009;3(11):939-43.

7. Filipic M, Umek A, Mlinaric A. Screening of Basidiomycete mushroom extracts for antigenotoxic and bio-antimutagenic activity. Die Pharmazie. 2002:57(6):416-20

8. Hu SH, Liang ZC, Chia YC, Lien JL, Chen KS, Lee MY, Wang JC Antihyperlipidemic and antioxidant effects of extracts from Pleurotus citrinopileatus. J Agric Food Chem. 2006;54(6):2103-10.

9. Dandapat S, Sinha MP, Kumar M, Jaggi Y. Hepatoprotective efficacy of medicinal mushroom Pleurotus tuber-regium. Environ Expe Biol. 2015;13(3):103-8.

10. El-kholy TA, Hassanen NH, Abbas HY. Protection of the mushroom (shiitake" lentinus-edodes) against carbon-tetrachloride-induced renal injury in rats. Life Sci J. 2013;10:1701-8.

11. Khan MR, Ahmed D. Protective effects of Digera muricata (L.) Mart. on testis against oxidative stress of carbon tetrachloride in rat. Food Chem Toxicol. 2009:47(6):1393-9.

12. Karadeniz A, Yıldııım A, Karakoç A, Kalkan Y, Celebi F. Protective effect of Panax ginseng on carbon tetrachloride induced liver, heart and kidney injury in rats. Revue Med Vet. 2009;160:237-43.

13. OECD Guidelines for the Testing of Chemicals. Organization for Economic; 1994 Feb 1

14. Misra HP, Fridovich I. The role of superoxide anion in the autoxidation of epinephrine and a simple assay for superoxide dismutase. J Biol Chem. 1972;25(10):247. 3170-5.

15. Ohkawa H, Ohishi N, Yagi K. Assay of lipid peroxidation in animal tissues by thiobarbituric acid reaction. Anal Biochem. 1978;95:351-8.

16. Todorova I, Simeonovo G, Kyuchukova D, Dinev D, And GV. Reference values of oxidative stress parameters ( ${ }^{*} \mathrm{MDA}<\mathrm{SOD}$ and $\left.\mathrm{CAT}\right)$ in dogs and cats. Comp Clin Pathol. 2005:13:190-4.

17. Hernández-Muñoz R, Díaz-Muñoz M, de Sánchez VC. Possible role of cell redox state on collagen metabolism in carbon tetrachloride-induced cirrhosis as evidenced by adenosine administration to rats. Biochim Biophys Acta. 1994;1200(2):93-9.

18. Parola M, Leonarduzzi G, Biasi F, Albano E, Biocca ME, Poli G, Dianzani MU. Vitamin $\mathrm{E}$ dietary supplementation protects against carbon tetrachloride-induced chronic liver damage and cirrhosis. Hepatology. 1992;16(4):1014-21.

19. Ogeturk M, Kus I, Colakoglu N, Zararsiz I, Ihan N, Sarsilmaz M. Caffeic induced nephrotoxicity and protective effect of betaine in Sprague Dawley rats. Urology. 2005;62:353-6.

20. Khan RA. Protective effects of Launaea procumbens on rat testis damage by CCl 4. Lipids Health Dis. 2012:11:103.

21. Nkosi CZ, Opoku AR, Terblanche SE. Effect of pumpkin seed (Cucurbita pepo) protein isolate on the activity levels of certain plasma enzymes in CCl4induced liver injury in low-protein fed rats. Phytother Res. 2005;19(4):341-5.

22. Dandapat S, Sinha MP. Antioxidant and anti-inflammatory activity of Pleurotus tuber-regium (Rumph. ex Fr.) Singer. Adv Biol Res. 2015;9(3):140-5.

23. Khan MR, Badar I, Siddiquah A. Prevention of hepatorenal toxicity with Sonchus asper in gentamicin treated rats. BMC Complement Altern Med. 2011;11(1):1

24. Khan MR, Rizvi W, Khan GN, Khan RA, Shaheen S. Carbon tetrachlorideinduced nephrotoxicity in rats: Protective role of Digera muricata. J Ethnopharmacol. 2009;122(1):91-9. 